\title{
Residential environment impact scale: Utilization of the Swedish version
}

Elise Svensson, Ida Kåhlin and Anette Kjellberg

The self-archived postprint version of this journal article is available at Linköping University Institutional Repository (DiVA):

http:// urn.kb.se/ resolve?urn=urn:nbn:se:liu:diva-142015

N.B.: When citing this work, cite the original publication.

Svensson, E., Kåhlin, I., Kjellberg, A., (2017), Residential environment impact scale: Utilization of the Swedish version, Scandinavian J ournal of Occupational Therapy, 28, 1-9.

https:// doi.org/ 10.1080/ 11038128.2017.1369158

Original publication available at:

https:// doi.org/ 10.1080/ 11038128.2017.1369158

Copyright: Informa Healthcare http://informahealthcare.com/ 
Title

Residential Environment Impact Scale - Utilization of the Swedish version

\section{Authors}

Svensson, Elise, Kåhlin, Ida and Kjellberg, Anette

Division of Occupational Therapy, Department of Social and Welfare Studies, Faculty of Health Sciences, Linköping University, Norrköping, Sweden.

\section{Corresponding author}

Ida Kåhlin

Linköping University

Department of Social and Welfare Studies

Division of Occupational Therapy

60174 Norrköping, Sweden

Ida.kahlin@liu.se 


\title{
Title
}

Residential Environment Impact Scale - Utilization of the Swedish version

\begin{abstract}
Background

The Residential Environment Impact Scale (REIS) is an assessment and consulting instrument designed to examine the impact of the residential environment on its residents and to develop recommendations for adapting this environment. Since REIS is new for occupational therapists in Sweden it is important to evaluate its utilization potential.
\end{abstract}

Aim

The aim was to examine the utility of the Swedish version of the Residential Environment Impact Scale (REIS-S) for adults living in residential settings.

\section{Material and Methods}

Twenty-two occupational therapists conducted 28 REIS-S assessments in residential settings including 92 older persons and persons with disabilities. In total, 44 questionnaires were answered before and after conduction of the assessment. The data was analysed using qualitative methods of analysis.

\section{Results}

The REIS-S showed both positive and negative dimensions of utility among occupational therapists working in residential settings. It provided support for making recommendations and contributed to effective assessments but was found time-consuming. The clinical 
relevance with REIS-S was positive since it met the needs expressed by the occupational therapists.

\section{Conclusions}

REIS-S seems promising according to utility in Swedish residential settings for adults. However, psychometrically testing is required for further establishing the utilization of the instrument.

Keywords Adults, assessment, residential environment, utility, participation

\section{Introduction}

Disability, age-related conditions or other conditions that create occupational problems can make it impossible to live in ordinary housing. In Sweden, the municipality is responsible for developing appropriate residential settings for people over the age of 65 (1), and for people with disabilities (2). In October 2015, almost 115000 people lived in such residential settings $(3,4)$. According to Swedish legislation these residential settings should be organized as private small apartments with areas for social interaction, hygiene, cooking and sleeping. The residents should also have access to a common area such as a common kitchen, dining and living rooms, and staff who support them (5). Policy objectives regarding these residential settings are that residents should be able to lead active everyday lives and to participate in society (6). However, since the home contributes to the quality of life and wellbeing of its residents and supports the feeling of independence and autonomy (7), moving into a residential setting is crucial and may result in a decrease of occupational participation and wellbeing. 
Planning and conducting interventions aiming to increase occupational participation for individuals in residential settings is one of the obligations of occupational therapists. However, in order to be able to practice in a knowledge-based and safe way, occupational therapists are in need of validated and reliable observation instruments that assess the effect of surrounding environments on individual or group activities and on participation $(8,9,10)$.

The Residential Environment Impact Scale, REIS, $(11,12)$ is an assessment and consulting instrument designed to examine the impact of the residential environment on its residents' occupational participation and to develop recommendations for adapting residential settings for adults with disabilities or other conditions that create occupational problems. REIS provides a structured way of assessing in what ways residential environments affect residents and how well these environments meet the needs of residents as a group. It also provides a summary of the strengths and weaknesses of the residential environment. This summary is used to generate recommendations for adapting the environment to better fit the needs of its residents. REIS was developed to fill a perceived gap in existing assessments on residential environment and its impact on residents $(11,12)$. REIS was initially designed for people with intellectual disability living in group homes, but was further developed to a tool that can be used in other residential settings as well. Since the first American version was published, REIS has been evaluated and revised, in collaboration with practitioners, to better meet the needs of occupational therapists in the field $(11,12,13,14)$.

REIS is based on the Model of Human Occupation, MOHO $(9,10)$. MOHO is a practice oriented, occupation focused, holistic and client centered model. It is evidence based and designed to complement other models and theories in occupational therapy. MOHO addresses 
how occupation is motivated, organized into everyday life patterns, and performed in the context of the environment (10). In MOHO the environment is defined as the particular physical, social, occupational, economic, political and cultural components of a person's contexts that impact upon the motivations, organization and performance of occupation. The environment provides opportunities and resources as well as demands and constraints on a person's occupational participation, i.e. engagement in meaningful and culturally appropriate activities in the areas of work, play, and activities of daily living $(9,10)$.

In 2013 REIS (11) was translated and adapted to the Swedish context with permission from the developer of the REIS. The two authors (AK, IK) individually translated and adapted the instrument. The authors compared their documents and after critical discussions they agreed upon a final version. This version was critically revised by the third author (ES). The adaptation was mainly related to the examples of objects given in the interview and observation guides. This research version, REIS-S (15), consists of 21 items organized into five domains, as shown in table 1. The administration of REIS-S involves data gathering, rating and making recommendations. The estimated time for administering and conducting an assessment is eight hours. The REIS-S manual contains guides for data gathering, which include an observation of the residential environment, observations of activities, and interviews with residents and staff $(11,15)$.

\section{[Insert Table 1 about here]}

The observation and interview guides are related to the five domains shown in table 1 . To complete the observations, the occupational therapist observes the residents and the staff performing three different activities with support from an observation guide. The guides for 
the interviews with residents and staff are semi-structured and include recommended global and in-depth questions. The manual also contains a detailed checklist for observations and interviews with residents $(11,15)$.

A synthesis of the data gathered from the observations and interviews is made by rating 21 items on a four-point ordinal scale. The scale corresponds to the following: $1=$ =needs major improvement, $2=$ needs some improvement, $3=$ appropriate or $4=$ strength. It is also possible to rate an item as not rated (NR) or not applicable (NA). Based on the ratings of the items, recommendations regarding adaptations in the residential environment are constructed for the items rated 1 (needs major improvements) or 2 (needs some improvements). The recommendation form enables the assessor to formulate recommendations and possible strategies for implementation in the residential setting in order to support the residents' occupational participation. The recommendations can be prioritized based on their importance, and given to the residential setting manager who is responsible for implementation and follow-up of the recommendations $(11,15)$.

REIS-S may be supportive for occupational therapists in practice when improving occupational participation for people living in residential settings. The Swedish disability policy including for example national legislation $(1,2)$ and the Convention on the rights of persons with disabilities (6) emphasizes the importance of removing barriers that hinder participation in daily activities in different settings. REIS-S may contribute to this since it focuses on the residential setting and how this matches the residents' preferences and needs.

In Swedish residential settings, residents should be able to lead active everyday lives and to participate in society (6). So far however, there has been a lack of occupational therapy 
assessment focusing on these policy objectives. Since REIS-S is focused on how well the residential environment is meeting the needs of residents as a group, and can be used to generate recommendations for adapting the environment to better fit the needs of its residents, it could fill an important gap in improvement of residential settings in Sweden. Since REIS is new for occupational therapists in Sweden it is important to evaluate the utilization potential of this innovation.

When evaluating the utilization potential of an innovation different aspects need to be considered. Polit and Beck $(16,17)$ describes three aspects for the utilization; implementation potential, clinical relevance and scientific merit for the innovation.

The aspect implementation potential includes transferability, feasibility, costs and benefits of the innovation. Transferability implies an evaluation on how well the innovation will match the setting and the correspondence between the amounts of clients the innovation, i.e. REIS-S, will serve. In addition the time required for implementing the assessment, administrative and financial structures are also of importance when evaluating the utility of the innovation. Feasibility is connected to resources that are available in practice for implementing the assessment such as do the occupational therapists have skills for using the REIS-S? Is the administration supportive and does the organizational climate promote the innovation? Cost/ benefit of the innovation imply material and non-material costs for implementing the innovation and conceivable risks for the implementation. In addition the potential benefits regarding change or to be in status quo including staff, clients and the organization is also urgent to evaluate. 
The second aspect when evaluating the utilization potential of an innovation is clinical relevance described as do the innovation have potential for solving problems and support decision-making for the occupational therapists? Have the innovation potential for being implemented and used in clinical practice?

The last aspect is scientific merit of the innovation. This focuses on the evaluation of the quality of the available research in the actual area such as validity, reliability and generalizability of the results in the studies in relation to the innovation.

Accordingly, the aim of the present study was to examine the utility of the Swedish version of the Residential Environment Impact Scale (REIS-S) for adults living in residential settings. The study focuses on two of the described aspects of utility: implementation potential, i.e. feasibility and transferability, and clinical relevance.

\section{Material and methods}

\section{Participant selection}

Since the REIS-S examine the impact of residential settings on residents', inclusion criteria for the study became occupational therapists (OTs) working with adults living in residential settings. OTs from seven municipalities in Sweden working with older persons or persons with intellectual or mental health problems living in residential settings were recruited through purposive and snowball sampling (17). The sampling procedure started with a purposive sampling which resulted in too few participants. Therefore the purposive sampling was combined with a snowball sampling. The already included participants were asked if they could recommend in their turn colleagues that also worked in residential settings with the 
target groups that corresponded to the study's inclusion criteria. The OTs were contacted via e-mail or telephone and were given information on the study. An information letter was also sent to those who were interested in participating. Informed consent to participate was collected from 13 OTs recruited through purposive sampling, and 15 recruited through snowball sampling chose to participate. Six OTs decided not to participate at an early stage. In total, 22 OTs completed the study. For the demographic characteristics of the OTs see table 2.

[Insert table 2 about here]

\section{Data collection}

An introduction and a follow-up questionnaire based on information on the different aspects of utility, i.e. implementation potential including feasibility and transferability, and clinical relevance $(16,17)$, was developed by the authors of the present study. The questionnaires were tested by two occupational therapists concerning the overall comprehension of the included questions. This led to some linguistic clarifications. Questions regarding demographics of the OTs' education and professional experience, their knowledge of MOHO (9) and experience of using assessments based on $\mathrm{MOHO}$ and their routines of conducting assessments prior to using REIS-S were also included in the introduction questionnaire. The follow-up questionnaire contained close-ended questions using mostly 4-point ordinal scales and nominal scales, including space for giving examples and comments. The questions were organized in accordance with the data collecting methods used in REIS-S and had nine questions that concerned the utility of the instrument. For examples of questions used in the questionnaires see table 3 . 


\section{[Insert table 3 about here]}

\section{Procedure}

Before conducting any assessments, the OTs attended a two-hour educational session on REIS-S where they were instructed on how to use the instrument, with opportunities to ask questions. At the beginning of this session the OTs $(n=22)$ completed the introduction questionnaire. All of the 22 OTs reported that they applied MOHO (11) in their daily work. Since the REIS-S evaluates how the residence meet the needs and desires of its residents the occupational therapists were requested to invite every resident in each setting to be involved. However the occupational therapists were also reminded to consider that all residents may not accept to participate. Each of the participating OTs was asked to conduct at least one assessment with REIS-S over a period of four weeks. In the end of the session the participants were invited to contact one of the authors (E.S.) after the educational session if they had questions about the REIS-S and the follow-up questionnaire.

In total, 28 assessments with REIS-S were conducted by the OTs; 17 of them conducted one assessment, four conducted two assessments and one conducted three assessments. A total of 92 residents from different target groups (older persons, or persons with intellectual disabilities or mental health problems) were included in the REIS-S assessments. The characteristics of the residents are further described in table 4. After using REIS-S at least once, the follow-up questionnaire was completed by 22 of the OTs participating in the study resulting in a total of 44 questionnaires

\section{[Insert table 4 about here]}




\section{Data analysis}

The two questionnaires including ratings and written comments constituted the basis for the analysis. The close-ended questions were categorised qualitatively in positive and negative aspects of utilisation. Rating scales such as no support and some support were categorized as negative aspects, and much support and very much support were categorized as positive aspects of utilization of the REIS-S.

The written comments were analysed using a directed content analysis (18). This deductive approach implies that the coding process is based on predetermined codes. The codes were based on existing theories concerning utility. The predetermined codes were feasibility, transferability, and clinical relevance $(16,17)$.

The written comments from the questionnaires were transcribed into separate documents. The amount of comments from each participant varied from two sentences on each question to more extensive descriptions.

The analysis started with reading the transcriptions thoroughly several times to get an overview of the material. The next step was to analyse the transcript, searching for data compatible with the predetermined codes. This included going back and forth in the transcripts and compare and control data with the theoretical descriptions of the concepts; feasibility, transferability and clinical relevance $(16,17)$. The first author performed this coding process. All authors had ongoing discussions throughout the whole analysis process to increase the validity of the results. To increase the dependability, the coding of data into the predetermined codes was discussed between the authors in a critical dialogue until consensus was achieved, in accordance with Krefting (19). 


\section{Ethical Considerations}

The study was conducted in accordance with the Declaration of Helsinki (20). The OTs, were informed that they could withdraw their participation in the study whenever they wanted without having to provide a reason. Informed consent was received after they had received information about the study. In addition the participants were also informed about confidentiality as well utilisation of data. During the educational session the OTs were informed that they were required giving the same ethical information to the residents and staff members in each residential setting that they themselves had received in the study. They were also asked to delete all personal information in the assessments except data on the residents' gender, year of birth and occurring disabilities.

\section{Results}

The results will be presented using the categories; feasibility, transferability, and clinical relevance.

\section{Feasibility}

All of the OTs who completed the follow-up questionnaire $(n=22)$ reported that they had used all data collection methods recommended in REIS-S. The checklist for interviewing residents was used by nearly half of the OTs, often as a tool for structuring the data after conducting the interview. Nearly all OTs reported that REIS-S had contributed to a more effective assessment of residential environments. The majority of the OTs found the observation and interview guides to be highly or very highly supportive when conducting the assessment indicating a strong feasibility. This indicates that the two-hour educational session and the 
manual gave sufficient support and skills for the OTs for managing to conduct the assessment. A few commented that REIS-S helped them to structure their assessment in a more effective way than before and that it gave a clearer picture of the residents' opinions of their home environment. They also reported that the observation guides, together with the manual, were sufficient for completing the observations. One OT commented in the follow-up questionnaire:

"[The recommendation form] provided me with clear goals for the enhancements needed [in the residential setting]" (OT 8)

Negative aspects regarding the extensive guides for data collection were commented on in the follow-up questionnaire. This indicates a low level of feasibility from some of the OTs. A few of them found the guides hard to use since they contained much text, while some found them easy to understand and use. The guides for observations was reported to enable the OTs to be more structured than when using informal assessments. One of the OTs stated that:

"Even though I was looking at the guide with the eyes of an occupational therapist, it was good to have a list [the walk-through observation guide] of specific aspects that I should consider." (OT 17)

Although the guides were extensive nearly all of the OTs reported that they had good or very good support from the observation guides and the interview guides. However, some OTs commented on problems regarding the memorability of REIS-S depending on the amount of data that was included. The OTs found the checklist for interviewing residents too detailed, which in turn reduced the memorability of REIS-S. Even if the feasibility of the REIS-S was 
mostly positive this limits the potential for implementation in practice. The interview guide for the interview with residents also contained much information that was hard to keep track of during the interviews. This sometimes resulted in losing focus during the interview. As one of the OTs stated:

"[it was] hard to keep focus on the questions I should be asking since there were many of them and they contained much text. Although I was prepared, I had to read up on it [about the questions] during the interview. I somewhat lost my focus on the residents." (OT 6)

Another OT reported that she had had to read the REIS-S guides several times before conducting observations and interviews. REIS-S was believed to contain more information than one could remember when performing the observations and interviews.

\section{Transferability}

The analysis showed that the time used by the OTs for administering and conducting REIS-S (range seven to nine hours) was considered reasonable by the majority of the OTs. The amount of time suggested in the manual, eight hours, was judged as reasonable for experienced users by nearly all of the OTs. However, some OTs stressed that the preparation before conducting the assessment with REIS-S was time-consuming, such as finding appropriate time for observation and interviewing, which in turn reduce the implementation potential the REIS-S into clinical practice. One OT reported:

"REIS-S is very time-consuming... it is useful but it is hard to find the time [to use the assessment]" (OT 11). 
Interviews with residents were reported to be very time-consuming, also reducing the implementation potential of the assessment. Most of the OTs used both global and in-depth questions when using the interview guides. One OT commented that using the in-depth questions required most time, while they also provided the most valuable information. Another OT, who conducted an interview with residents lasting more than two hours and 30 minutes, reported that:

"The time was worth it since a lot of interesting aspects emerged" (OT 12).

\section{Clinical relevance}

According to the introduction questionnaire, nearly all of the OTs conducted assessments regarding residential environment in their daily work and reported that they needed an instrument assessing residential environments in residential settings. Further the OTs stated that relevant characteristics for an assessment being used in a residential setting was that it should be structured, easy to administer, usable for people with different diagnoses and residential environments, and not time-consuming. They also stated that it should include different methods for gathering data, and should consider issues of accessibility, the individual's interaction with the environment, and conditions for occupational performance. Moreover, they also expressed that an assessment for being clinically relevant was that it should be easy to understand and simple to use when suggesting recommendations. The follow-up questionnaire showed that REIS-S corresponded to most of these expectations.

The OTs reported that REIS-S contributed to a clearer view of how the residents experienced their home, and gave opportunities for making recommendations based on this. This shows that the REIS-S has potential for supporting occupational therapists' decision-making in 
practice. The REIS-S also met the requirements for an instrument being easily communicating recommendations and an instrument that considered the residents' interaction with the environment. A few OTs stated that the physical environment could have been further emphasised in the observation of activities, since it affected the residents' opportunities for participation.

Regarding the REIS-S scale for rating the 21 items, nearly all the OTs regarded it as fairly good or good. However, they also reported that it was problematic to use it for synthesizing the collected data. One OT reported that:

"It's hard to put a general number [a rating value] on it that would be valid for 18 different persons in need of different types of support” (OT 4).

Most of the participants agreed upon they were going to continue to use the REIS-S in their clinical practice. Nevertheless some occupational therapists answered that there were challenges to use it in residential settings for people with dementia since interviewing was not a suitable data collection method for the target group.

\section{Discussion}

This study shows that the utility of REIS-S have both positive and negative dimensions. The OTs reported that REIS-S contributed to a more structured and systematic assessment compared to when not using REIS-S. According to the clinical relevance this facilitated the process of developing recommendations for a group of residents living in residential settings in comparison with previous way of working. 
The extensive guides limit the feasibility of the REIS-S and it's utility in clinical practice. It is acknowledged that there are several formats for the data gathering. On the other hand these are provided to support the OTs when evaluating both the physical and social environment for a group of residents that may have different disabilities. In a previous study by Alfredsson Ågren and Kjellberg (21) an observational assessment; the Volitional Questionnare (22) was examined. The time required for administering including preparation, observation and completion of the forms for this assessment showed initially that the time needed for the OTs was substantial. However, time decreased after performing each assessment based on in total six conducted assessments. One hypothesis is that the same pattern may be found for the time required for the REIS-S but this needs to be investigated in future research.

The feasibility regarding the skills needed was reported as low since the guides for data gathering contained a large amount of text. This meant it was hard to focus on the residents in the interview situation. This hinders the possibilities of establishing a good relationship with residents (23), which may make it harder to summarize information from the residents. The fact that the OTs had to review the guides before data collection shows a need for using the manual when collecting data for an assessment with REIS-S. This indicates that using the REIS-S requires regular use over a longer period of time before the OTs becomes skilled in using the assessment, probably also including reduced time for conducting the REIS-S.

The assessment was reported as time-consuming. The large amount of time needed for administering REIS was also pointed out in a previous study (13). The fact that the instrument was time-consuming and comprehensive also affected the transferability negatively, even though the instrument was reported to meet most of the OTs' expectations for an assessment 
to be used in residential environments. Long administration time is a hindrance for the transferability of REIS-S since practitioners' time is often limited (24). On the other hand, occupational therapists should conduct assessments and investigate the need for changes in the physical and social environment in residential settings $(9,25)$. Since the REIS-S is an instrument that can be used for different populations with various disabilities there is need for several data collection methods to be used in order to develop reliable recommendations. This will increase the amount of time needed for the OTs in comparison with earlier working methods.

The theoretical framework for the REIS-S, the MOHO, has been developed over four decades and several studies have been published based on it. Consequently the REIS-S is based on a solid theoretical foundation $(9,10)$. Several MOHO-based assessments have also been developed which can be considered as resources since some of these - for example, the Assessment of Motor and Process Skills (26) the Volitional Questionnaire (22) and The Assessment of Communication and Interaction Skills (27) - can be used in combination with the REIS-S. This strengthen the clinical relevance of REIS-S in Sweden.

Our study shows that REIS-S contributes to a more structured and systematic procedure for assessment and giving recommendations. Since the residential environment is of importance for the residents' participation $(7,28,23)$, an assessment like REIS-S that measures the environmental impact on its residents and staff may contribute to a deeper understanding of the residents' situation. REIS-S also gives OTs the opportunity to make recommendations for alterations concerning the residential environment such as technical aids and supervising staff in increasing the residents' occupational participation (15). 
The OTs in the study were mostly involved in performing assessments from an individual perspective, such as the Volitional Questionnaire (22) and Occupational Self-assessment (29), and were therefore unaccustomed to making assessments on a group level. This needs to be considered when reflecting upon the results that revealed it was challenging for them to perform assessments in relation to a group perspective. Using the REIS-S helps the OT to broaden the focus and include the group perspective. Nevertheless, this does not exclude the possibility that individual residents need to have tailor-made interventions. In such cases it is important to investigate in what ways these individual-based interventions may influence the whole group of residents. It is possible to assume that these interventions can be positive for more than the single resident. On the other hand, the opposite could be true and then the OT needs to decide what can be done that would benefit the whole group of residents.

A Swedish study performed in the area of municipal elderly care reported that OTs considered that insufficient time was a hindrance when supervising staff (30). Therefore, it is necessary for OTs to develop strategies for consulting that are timesaving and effective. We believe that using REIS-S could support this development since the OT is provided with a structured way of collecting data and for developing actions for a whole residential setting. This might influence the amount of time required when performing an assessment. Furåker and Nilsson (31) propose, based on their study among Swedish OTs working in municipal healthcare, that there is an urgent need to examine the competence required by OTs when working consultatively. If OTs are going to further develop the consultative role including support and supervision, it is necessary to use an assessment that emanates from a group perspective for obtaining data when developing effective recommendations for the collective resident group. REIS-S may therefore help the OTs to improve their skills when conducting assessments in residential settings. 
After this study was conducted, a revised version of REIS (12) and REIS-S (32) was

published where some of the weaknesses found in the present study were accounted for. With this in mind, the published version of REIS-S may have a higher level of utility, but this must be further investigated. In addition, an evaluation of the validity and reliability of the now published version of REIS-S is urgent.

\section{Methodological considerations}

The results of the study is not generalizable to the entire population of living in residential settings. Nevertheless despite a relatively small number of participants $(n=22)$ the study indicates potential opportunities for the REIS-S being used in Sweden. Studies with larger samples with a broad representation of different residential settings examining validity, reliability and utility of the REIS-S is urgent.

The present study is mostly based on that the OTs used the REIS-S once. Therefore further studies are required in order to be able to further evaluate transferability $(16,17)$. This, since it is reasonable to assume that having used an assessment several times may have an impact on the time being used.

The directed content analysis implied to use an existing theory which could be considered as limitation since there is a risk that the theory is incomplete or need to be further developed. The predetermined codes, feasibility, transferability and clinical relevance were based on theory concerning utilization $(16,17)$ which gave support to the validity of the study. This includes also an inherit limitation since the researchers approach the data with an informed but strong bias. 
The OTs mainly worked in residential settings for older people; thus the results can be considered to have the potential to be transferred to other residential settings for older people. It may also be possible to transfer the results of the present study to other types of residential settings for other client groups in Sweden since the physical and social environment in residential settings for client groups such as persons with intellectual, neuropsychiatric or psychiatric disabilities and for older people are similar (5).

\section{Conclusion}

The REIS-S showed both positive and negative dimensions of utility among OTs working in residential settings. This was the first study conducted in a Swedish context and the results revealed that the REIS-S seems promising according to feasibility, transferability and clinical relevance in Swedish residential settings for adults. The study provided valuable information for further development of the instrument. Psychometrically testing is required for further establishing the utilization of the REIS-S.

\section{Acknowledgements}

The authors would like to express their gratitude to all occupational therapists that participated in this study. We would also like to thank Clinical Associate Professor Gail Fisher, Department of Occupational Therapy at University of Chicago, Illinois, USA for valuable comments during the writing process of this article. 


\section{Declaration of interest}

The authors report no conflicts of interest. The authors alone are responsible for the content and writing of the paper.

\section{References}

1. SFS (Svensk Författningssamling) [Swedish Code of Statues]. 2001:453. Socialtjänstlagen (in Swedish).

2. SFS (Svensk Författningssamling) [Swedish Code of Statues]. 1993:387. Lag om stöd och service till vissa funktionshindrade [The Act Concerning Support and Service for Persons With Certain Functional Impairments] (in Swedish).

3. Socialstyrelsen [National Board of Health and Welfare]. Insatser och stöd till personer med funktionsnedsättning. Lägesrapport 2016 [Efforts and Support Concerning Persons with Functional Impairments - Progress Report 2016]. Stockholm: Socialstyrelsen; 2016 (in Swedish).

4. Socialstyrelsen [National Board of Health and Welfare]. Vård och omsorg om äldre. Lägesrapport 2016 [Health and Social Care of the Elderly - Progress Report 2016]. Stockholm: Socialstyrelsen; 2016 (in Swedish).

5. Socialstyrelsen [National Board of Health and Welfare]. Bostad med särskild service och daglig verksamhet - en forskningsöversikt [Housing with Certain Services and Daily Activities - A literature review]. Stockholm: Socialstyrelsen: 2011 (in Swedish).

6. Government Offices of Sweden [Internet]. Goals and visions. [updated 2015 March 17; cited 2016 December 19]. Available from: URL: http://www.government.se/governmentpolicy/social-care/goals-and-visions/ 
7. Gitlin LN. Conducting Research in Home Environments: Lessons Learned and New

Directions. Gerontologist 2003; 43:628-637.

8. Swedish Association of Occupational Therapists [Internet]. Competence Descriptions for Occupational Therapists. [published 2015; cited 2016 June 23]. Available from:

URL:http://www.arbetsterapeuterna.se/Min-profession/Kompetensutveckling/Forbundetsforlag/Competence-Descriptions-for-Occupational-Therapists-2015/

9. Kielhofner G. Model of Human Occupation: Theory and Application. 4th ed. Baltimore: Lippincott, Williams \& Wilkins; 2008.

10. Taylor R R. Kielhofner's Model of Human Occupation : Theory and Application. 5th ed. Baltimore: Lippincott, Williams \& Wilkins; 2017.

11. Fisher G., Kayan E., Arriaga P. \& Less C. The Residential Environment Impact Survey (REIS). Version 3.0. Chicago, University of Illinois; 2013.

12. Fisher G, Forsyth K, Harrison M, Angarola R, Kayhan E, Noga PL et al. The Residential Environment Impact Scale (REIS). Version 4.0. Chicago, University of Illinois; 2014. 13. Fisher G. \& Kayhan E. Developing the Residential Environment Impact Survey Instruments Through Faculty - Practitioner Collaboration. Occup Ther Health Care 2012;26:224-239.

14. Fisher G. The Residential Environment Impact Survey. AOTA Developmental Disability - Special Interests Section Quarterly 2004;27:1-4.

15. Kjellberg A. \& Kåhlin I. Bedömning av boendemiljö i särskilda boenden - REIS-S [Residential Environment Impact Scale - REIS-S]. Research version, 2013 (unpublished). 16. Polit DF. \& Beck CT. Nursing research: Principles and methods. 7th ed. Philadelphia: Lipincott; 2004.

17. Polit D. \& Beck CT. Nursing research: generating and assessing evidence for nursing practice. 8th ed. Philadelphia: Lippincott, Williams \& Wilkins; 2008. 
18. Hsieh HF. \& Shannon SE. Three approaches to qualitative content analysis. Qual Health Res 2005;15: 1277-88.

19. Krefting L. Rigor in qualitative research: The assessment of trustworthiness. Am J Occup Ther 1991;45:214-22.

20. World Medical Association. Declaration of Helsinki - Ethical principles for medical research involving human subjects. 1964/2013.

21. Alfredsson Ågren, K. \& Kjellberg A. Utilization and content validity of the Swedish version of the Volitional Questionnaire. Occupational Therapy in Health Care, 2008; 22:163176.

22. Alfredsson Ågren K. \& Kjellberg A. Bedömning av Viljeuttryck - VQ-S [Volitional Questionnaire - VQ-S]. Stockholm: Sveriges Arbetsterapeuter; 2015 (in Swedish).

23. Heller T. Residential Settings and Outcomes for Individuals with Intellectual Disabilities. Curr Opin

24. Robbins I., Gordon A., Dyas J., Logan P. \& Gladman J. Explaining the barriers to and tensions in delivering effective healthcare in UK care homes: a qualitative study. BMJ Open 2013;3:1-9.Psychiatry 2002;15:503-08.

25. Swedish Association of Occupational Therapists. Code of Ethics for Occupational Therapists. Nacka: Sveriges Arbetsterapeuter; 2016.

26. Fisher AG. Assessment of Motor and Process Skills: User manual 4th ed. Vol 2. Fort Collins, CO: Three Star Press; 2001.

27. Haglund L. \& Kjellberg A. Bedömning av kommunikations- och interaktionsfärdigheter ACIS-S. [Assessment of Communication \& Interaction Skills - ACIS-S]. Stockholm: Sveriges Arbetsterapeuter; 2012 (in Swedish).

28. Larsson Lund M, Nygård L. Occupational life in the home environment: the experiences of people with disabilities. Can Journal Occup Ther. 2004; 71: 243-251. 
29. Sjöberg EM. Min Mening - bedömning av kompetens och värderingar genom

självskattning. [Occupational Self Assessment - OSA]. Stockholm: Förbundet Sveriges

Arbetsterapeuter; 2012 (in Swedish).

30. Pros C. \& Kjellberg A. Supervision in Occupational Therapy regarding Rehabilitation of Elderly People in Sweden. Scand J Occup Ther 2008;15:221-29.

31. Furåker C. \& Nilsson K. The consultative work of occupational therapists working in municipal healthcare. Scand J Occup Ther 2011;18:101-08.

32. Kjellberg A. \& Kåhlin I. Miljöns betydelse för delaktighet i aktivitet - Instrument för bedömning och rekommendation för särskilda boenden (REIS-S). [Residential Environment Impact Scale - REIS-S] Nacka: Sveriges Arbetsterapeuter, 2015 (in Swedish).

Tables and Figures

Table 1. Assessment domains and items of REIS-S (Kjellberg \& Kåhlin, 2013)

\begin{tabular}{|l|l|}
\hline Domain & Item \\
\hline & Safety and Accessibility of Physical Space \\
& Adequacy of Space \\
& Sensory Environment \\
& Cognitive and Visual Supports \\
& Homelike Qualities \\
& Natural Environment \\
\hline 2. Objects \& Equipment & ADL/IADL Objects \\
& Leisure Objects \\
& Adaptive Equipment, Tools and Aids \\
\hline 3. Support for & Activities of Daily Living \\
Occupational Participation & Instrumental Activities of Daily Living \\
& Leisure and Recreational Activities \\
& Productivity \\
& Community Activities \\
& Schedule/Routine \\
\hline 4. Social Environment & Relationship with Staff/Caregiver/Carer Relationship with Others \\
& Inside Home/Facility \\
& Level of Assistance \\
\hline 5. Opportunities for & Decision-making \\
Self-determination & Empowerment \\
& Autonomy and Independence \\
\hline
\end{tabular}


Table 2. Demographic characteristics of the occupational therapists $(n=22)$ :

\begin{tabular}{lc}
\hline & Total \\
\hline Gender & \\
Women/men $n$ & $21 / 1$ \\
Years of practice & \\
$\begin{array}{l}\text { Years since graduation median (mode) } \\
\text { Years at current workplace median (mode) }\end{array}$ & 2 (1) \\
& \\
Education & \\
BScOT $n$ & \\
MScOT $n$ & 21 \\
Residential Setting & 1 \\
Residence for older persons, age $>65 n$ & \\
Residence for persons with disabilities $n$ & 18 \\
& \\
Experience of assessments prior to using & \\
REIS-S & \\
Conducted informal assessments $n$ & \\
Used standardized assessments $n$ & 15 \\
Assessments used by \\
occupational therapists \\
$\begin{array}{l}\text { Assessment of Motor and Process Skills, } \\
\text { AMPS } n\end{array}$
\end{tabular}

\footnotetext{
${ }^{\mathrm{a}}$ Fisher AG. Assessment of Motor and Process Skills: User manual $4^{\text {th }}$ ed. Vol 2. Fort Collins, CO: Three Star Press; 2001., b Alfredsson Ågren K, Kjellberg, A. Bedömning av Viljeuttryck - VQ-S [Volitional Questionnaire - VQ-S]. Stockholm: Sveriges Arbetsterapeuter; 2015., ${ }^{\mathrm{c}}$ Sjöberg EM. Min Mening - bedömning av kompetens och värderingar genom självskattning. [Occupational SelfAssessment - OSA]. Stockholm: Förbundet Sveriges Arbetsterapeuter; 2012., ${ }^{\mathrm{d}}$ Norrby E, Lindahl 1. Dialog om arbetsförmåga, DOA [Dialogue about Working Ability - DWA]. Stockholm: Förbundet Sveriges Arbetsterapeuter; 2013
} 
Table 3. Examples of questions used in the Questionnaires

\begin{tabular}{|c|c|}
\hline Utility aspects & Examples of questions in the questionnaires \\
\hline \multirow[t]{2}{*}{ Feasibility } & $\begin{array}{l}\text { In the manual there are guides which should be helpful when } \\
\text { conducting the observation of the residential environment/observation } \\
\text { of activities/interview with residents/interview with staff. How much } \\
\text { support did these guides give you? }^{2}\end{array}$ \\
\hline & $\begin{array}{l}\text { Did REIS-S contribute to a more effective assessment of residential } \\
\text { environments compared to the methods you have used before? }\end{array}$ \\
\hline \multirow[t]{2}{*}{ Transferability } & $\begin{array}{l}\text { How long did it take to complete and document the observation of the } \\
\text { residential environment/observation of activities/interview with } \\
\text { residents/interview with staff/recommendations/ratings in the rating } \\
\text { form/writing recommendations/giving recommendations? }\end{array}$ \\
\hline & $\begin{array}{l}\text { After having conducted your assessment, do you believe you have } \\
\text { sufficient information to continue using REIS-S? }\end{array}$ \\
\hline \multirow[t]{3}{*}{$\begin{array}{l}\text { Clinical } \\
\text { relevance }\end{array}$} & $\begin{array}{l}\text { Do you need an instrument that assesses the environment in } \\
\text { residential settings? }\end{array}$ \\
\hline & $\begin{array}{l}\text { Have you missed or felt the need for an assessment that assesses the } \\
\text { residential environment in residential settings? If yes, what } \\
\text { requirement do you have on such an assessment? }\end{array}$ \\
\hline & Are you going to use REIS-S in your work again? ${ }^{2}$ \\
\hline
\end{tabular}

Table 4. Characteristics of residents in the study $(n=92)$

\begin{tabular}{lc}
\hline & Total \\
\hline Gender (women/men) & $56 / 36$ \\
Age of residents median (mode) & $85(95)$ \\
Older persons, age $>65 n$ & 72 \\
Persons with disabilities $n$ & 20
\end{tabular}

